US Army Corps of Engineers

\title{
Steel-Shot Method for Measuring the Density of Soils
}

\author{
by Chad A. Gartrell, Dr. Lillian D. Wakeley, Dr. Reed B. Freeman,
} Dr. Ernest S. Berney, and Julie R. Kelley

ABSTRACT: The density of soil is crucial in engineering, construction, and research. Standard methods to determine density use procedures, equipment, or expendable materials that limit their effectiveness in challenging field conditions. Some methods require burdensome logistics, or have time requirements that limit their use or the number of tests that can be executed. A test method, similar to the sand-cone method, was developed that uses steel shot as the material to which a volume of soil is compared to calculate soil density. Steel shot is easily recovered and reused, eliminating the need for specialty sand and calibrated cones or containers, and allows rapid determination of the volume of displaced soil. Excavated soil also provides measurements of total mass and moisture content. Volume, mass, and moisture content are applied in simple calculations to determine wet and dry densities and unit weight of the soil. Proficiency in performing the test can be achieved with minimal training, and the required kit can be assembled for a reasonable cost. Field uses of the method in dry environments in a variety of soil types demonstrated that the method can produce repeatable results within 2 percent of the values of soil density determined by traditional methods, with advantages in logistics.

INTRODUCTION AND PREVIOUS WORK: The density of soil is a property that is important in many applications, such as agriculture, engineering, construction, and research. Measurement of soil density can be performed using several accepted methods, including those listed in Table 1. The method used in a specific field application is selected based on parameters considered important by the field team, including logistics, availability of specialized equipment or materials, method complexity, and time to execute the test.

In military field activities, such as expedient construction and military site characterization, none of the standard methods for determining soil density meet the needs of the circumstances to be logistically friendly, simple, repeatable, and adaptable for challenging environments. In these field situations, data for in situ soils must be collected rapidly by teams with frequent changes in personnel. There is typically no opportunity to return to the site and re-run the tests. The lack of a 
logistically suitable test for soil density in military operations has led to the consideration of developing a new method by adapting an existing protocol to more challenging conditions.

\begin{tabular}{|c|c|}
\hline \multicolumn{2}{|c|}{$\begin{array}{l}\text { Table 1. American Society for Testing and Materials (ASTM) } \\
\text { standard test methods for soil density. }\end{array}$} \\
\hline ASTM Method Title & Source \\
\hline D6938: Density of soil — by nuclear methods & ASTM 2008d \\
\hline D1556: Density and unit weight of soil — by sand-cone method & ASTM 2007 \\
\hline D2167: Density and unit weight of soil - by the rubber balloon method & ASTM 2008c \\
\hline D2937: Density of soil — by the drive-cylinder method & ASTM 2004 \\
\hline D4914: Density of soil - by the sand replacement method in a test pit & ASTM 2008b \\
\hline
\end{tabular}

Other researchers have compared the results of soil density measurements of different combinations of the methods listed in Table 1. Abaza (2006) compared nuclear density measurements to sand-cone measurements in the field for base-course soils placed for asphalt pavement. He determined a relationship between data obtained by the two methods and concluded that although the differences for dry density are smaller than for wet density, differences between the two techniques of measuring density are not significant for acceptance purposes. However, Abaza (2006) also noted that the differences in moisture content were significant, causing him to consider the nuclear gauge unreliable for determinations of soil moisture.

McCook and Shanklin (2000) compared results of field density test methods, including sandcone, nuclear gauge, density-drive cylinder, and rubber balloon tests. They described the special operations required to operate the nuclear gauge, such as calibration of the instrument before testing, preparation of the surface, and development of correction factors. In general, results from the nuclear gauge and sand-cone methods were similar, although the standard deviation for duplicate tests was smaller for the nuclear gauge method.

McCook and Shanklin (2000) reported specific problems encountered with the sand-cone method, including physical challenges of using the sand in high humidity and errors attributable to personnel changes. The drive cylinder method gave more consistent results than the sand cone in wet field conditions for interlayered clayey silty sand [Unified Soil Classification System (USCS) (ASTM 2006) class SC] and plastic silty sandy clay (class CH). All methods gave less consistent results in natural (nonengineered) soils than in fill (engineered soils). Calibrating the sand for the sand cone was unreliable at some locations, even for experienced operators, because in high relative humidity, the sand clumps and does not flow readily.

Noorany et al. (2000) compared sand-cone, nuclear, and drive-cylinder methods on soils compacted to a known water content and dry density under controlled laboratory conditions. They experienced the widest range of variability in moisture content from nuclear density measurements, and the least variability with the sand-cone method. For example, the average standard deviation for the nuclear method was 0.77, while all other methods had an average standard deviation of 0.30 . In their work, the drive-cylinder method underestimated field density, especially for gravelly soils. 
The experience of previous researchers indicates that no single method is outstanding in all soil types and conditions. Nonetheless, all methods in Table 1 were considered when choosing the basis for modifications to meet the needs of expedient construction and military operations. The following section reviews the processes followed in selecting the best candidate method for the applications and deciding how to modify that method to improve its field use. The USCS was used because it is the soil classification system used in most engineering applications, and it was used in the previously published work referenced here.

APPROACH: Each standard method listed in Table 1 can reproducibly provide a value for the density of some soil types. They each offer some advantages to the user, yet have restrictions or limitations. These test methods and materials are acceptable in the commercial, industrial, and research worlds, where daily activities may accommodate a method that is not rapid, not easily portable, or is logistically complex. To develop a method to fit an increased operational tempo with decreased logistical challenges, the decision was made to modify an accepted method, thereby capitalizing on its strong traits and minimizing its limitations. The approach was to examine the accepted methods, noting their advantages and disadvantages, and choose the best fit for the desired application that required the least modification.

A nuclear energy source in a nuclear density gauge measures soil density and other properties. The device compares the detected rate of gamma radiation-as it is transmitted through the soil — with a transmission through a standard calibration block. The nuclear density gauge was eliminated because use of a radiation source requires adherence to regulations of the Nuclear Regulatory Commission in the USA and on board USA aircraft, as well as adherence to local laws and regulations of the host nation. This is an unacceptable complexity in fast-paced operations and activities for which the equipment must be transported across international boundaries.

In the drive-cylinder method, a small drive cylinder, open at both ends, obtains a relatively undisturbed sample of soil. The open cylinder is driven into the soil. Once flushed, the material around the cylinder is excavated, and the cylinder is removed. Knowing the volume of the cylinder and its mass when empty, the unit weight of the soil in the cylinder can be determined. Drying a sample of the soil from the cylinder provides the data to determine soil density. The drive cylinder was eliminated from the list because our field experience showed that it is almost impossible to drive cylinders into coarse-grained or cemented soils.

In the balloon test, a rubber bladder and water determine soil density through the method of volume replacement. The bladder is lowered into a small test hole on the soil surface, with water from a reservoir under a small amount of pressure filling the bladder to insure the bladder assumes the shape of the hole. The volume of water used to fill the hole determines the volume of soil taken from the test hole. Soil moisture content is measured by drying the soil from the test hole, and soil density is calculated from volume and moisture content. The rubber balloon itself is not suited for rugged environments, especially for soils with gravel or sharp aggregate particles that could cut the bladder.

The sand-cone method is similar to the balloon method with respect to the principle of volume replacement. Specialty sand fills a small test hole. The volume of sand required to fill the hole is measured. The soil removed from the test hole is dried to determine moisture content. The sandcone method was rejected because it requires specialized equipment (cone and sand bottle) that 
must be calibrated; uses specialized sand that is bulky to ship to field sites and cannot be reused; and this specialized sand is not readily available internationally.

The sand-cone method was chosen as the basis for the new procedure. It appeared that the sandcone method could be modified to simplify equipment and procedures without losing accuracy or repeatability, while reducing time and logistical burdens to perform the test. The key points in this decision were:

- The sand cone method is a widely accepted method.

- It can be applied in a wide range of soil types from high-plasticity clay $(\mathrm{CH})$, to sands and silts (GS or SM), to gravelly soils (GW or GP) (designations in parentheses are as defined in ASTM 2006).

- The method uses volume replacement with specialty sand, a drawback that could be mitigated if the sand were replaced with a more user-friendly material that is easily reusable.

- Although it requires calibration, the equipment and procedures are simple.

DEVELOPMENT AND DESCRIPTION OF NEW METHOD: Assuming the sand-cone method would be a suitable basis for an improved method, the concept of volume replacement with a material other than sand was investigated. Plastic shot as the volume-replacement material was the first idea because it is lightweight and portable, and could likely be dried rapidly in a small microwave oven. Plastic shot proved to be unsuitable because the material is soft relative to soil minerals, and reuse of plastic shot causes the surfaces of individual particles to become rough. The increased surface roughness decreases the ability of the shot to pack consistently under free-fall when poured into a test hole. The plastic shot also was difficult to remove from the test hole.

Ultimately, stainless steel shot was selected as the volume-replacement material. Because of its hardness, it does not roughen over time with reuse, so the packing of the balls in a test hole remains consistent. The stainless steel does not rust or degrade in the presence of moisture. The material is easily washed and can be dried on a hot plate, or it can be air-dried under direct sunlight. The shot is also less sensitive to changes in the method of placement (poured into the hole from different heights above the hole). Stainless steel is ferromagnetic, so the shot can be retrieved easily from the test hole using commercially available magnets. Field trials indicate that after six or seven uses, it is necessary to rinse, screen, and dry the shot to eliminate foreign matter that may collect on the spheres during use.

It was necessary to compromise between small particles that would conform easily to irregular soil surfaces and larger particles that would be easier to handle and retrieve. Regardless, the shot had to have a uniform size to ensure no changes in gradation due to segregation. The diameter chosen was $4.8 \mathrm{~mm}$. The stainless steel shot used was Type 440C (ASTM 2008a), with a density of $7689 \mathrm{~kg} / \mathrm{m}^{3}$. The Rockwell hardness of these balls is 58 (ASTM 2009a). The average cost of the shot, as of January 2010, is about US\$13 (CAN\$13.50) per 1000 balls.

The calibrated bottle and cone required for the sand-cone test were eliminated from our method. Instead, a graduated cylinder is used to determine the volume of shot required to fill the hole. This is accomplished because steel-shot particles keep their consistent spherical shape with use, 
and pack consistently in the cylinder and the test hole. The method developed here uses shot in the driest state possible, to avoid accumulation of condensation in humid environments.

The procedure for the steel-shot density (SSD) method can be summarized as follows:

1. A test hole is excavated in the soil to be tested.

2. The hole is filled with the steel shot, which has a predetermined bulk density (Figure 1).

3. The volume of the shot used to fill the hole is measured.

4. The in-place wet density of the soil is measured by dividing the wet mass of soil removed from the hole by the volume of the hole as measured by the steel shot.

5. The water content of the soil is determined using the soil from the test hole.

6. The dry mass of the material and the inplace dry density are calculated from the measured values of the wet soil mass, water content of the soil, and volume of the test hole.

FIELD DEMONSTRATION OF THE SSD METHOD: After laboratory trials of the SSD method, the method was applied at one field site in the USA and one in Australia to compare SSD with other standard methods in the same soils. Data from the USA field trials came from multiple research projects for which soil test sections were constructed from different materials at the U.S. Army Engineer Research and Development Center in Vicksburg, Mississippi. The SSD method was compared with the nuclear gauge, sand-cone, and rubber-balloon methods.

Table 2 gives data from field trials with SSD and three other methods in two different soil

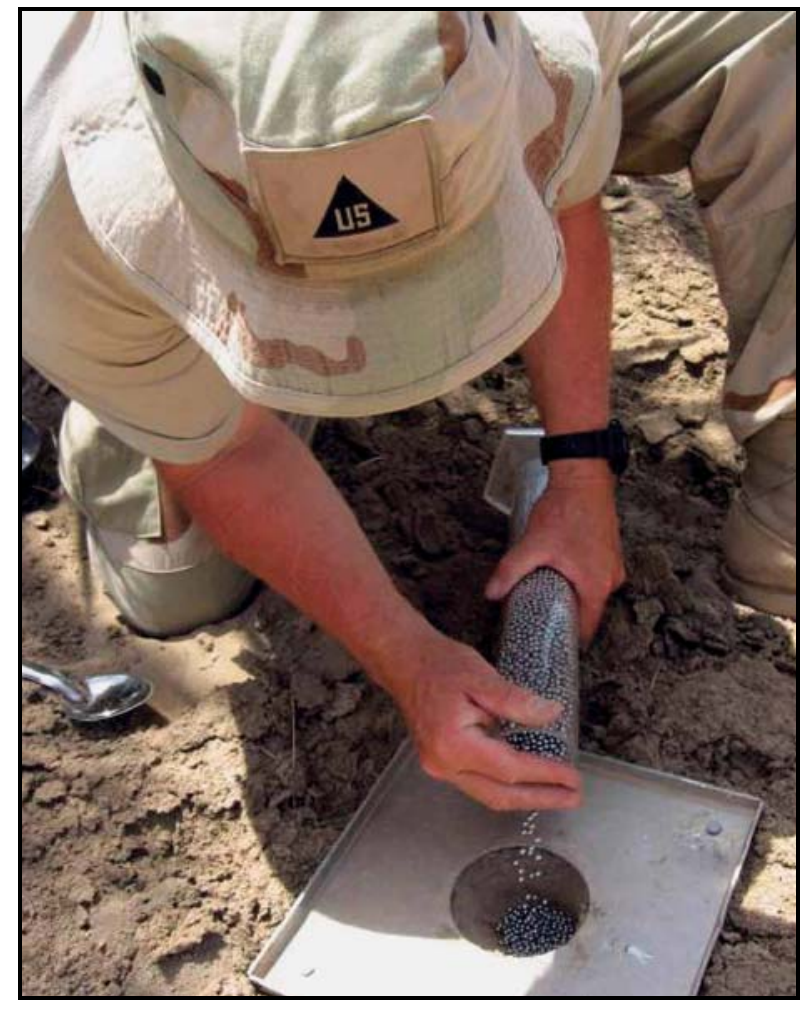

Figure 1. Pouring of the steel shot into a test hole using a graduated cylinder. types (USCS classes SM and CL). Because the sand cone most closely resembles the steel-shot method, this was the preferred test for comparison when possible. If sand-cone data were not available, data from the nuclear gauge method were used for comparison. This was especially convenient in the SM soils because the nuclear gauge and sand-cone methods showed good agreement. As shown in Table 2, a variation of less than \pm 2.0 percent was found in side-by-side comparisons of the steel-shot method with other methods. In most cases, the variation was at or below 1.0 percent. These differences are acceptable in expedient or military construction applications, where the expectation is an estimate of soil density within a tolerance of $80 \mathrm{~kg} / \mathrm{m}^{3}$. 


\begin{tabular}{|c|c|c|c|c|c|c|}
\hline \multicolumn{7}{|c|}{$\begin{array}{l}\text { Table } 2 \text {. Dry densities measured using the steel-shot method compared with data } \\
\text { obtained by other standard methods, from field trials in Vicksburg, MS. }\end{array}$} \\
\hline \multirow[b]{2}{*}{ Soil USCS ${ }^{a}$} & \multirow[b]{2}{*}{ Date } & \multicolumn{4}{|c|}{ Dry Density, kg/m ${ }^{3}$} & \multirow[b]{2}{*}{ Percent Difference } \\
\hline & & Nuclear Gauge & Sand Cone & Rubber Balloon & Steel Shot & \\
\hline \multirow[t]{2}{*}{ SM } & \multirow[t]{2}{*}{17 March 2005} & 2090 & 2101 & 2108 & 2119 & 0.8 \\
\hline & & 2094 & 2098 & - & - & - \\
\hline \multirow[t]{2}{*}{ SM } & \multirow[t]{2}{*}{30 March 2005} & 2063 & - & - & 2100 & 1.8 \\
\hline & & 2073 & - & - & 2084 & 0.5 \\
\hline \multirow[t]{2}{*}{ SM } & \multirow[t]{2}{*}{04 April 2005} & 2094 & - & 2153 & 2090 & -0.2 \\
\hline & & 2066 & - & 2138 & 2062 & -0.2 \\
\hline \multirow[t]{2}{*}{ SM } & \multirow[t]{2}{*}{05 May 2005} & 2132 & - & 2148 & 2105 & -1.3 \\
\hline & & 2105 & - & 2122 & 2084 & -1.0 \\
\hline \multirow[t]{3}{*}{ SM } & \multirow[t]{3}{*}{17 May 2005} & 1989 & - & 2057 & 2010 & 1.0 \\
\hline & & 1991 & - & 2036 & 2002 & 0.6 \\
\hline & & 1985 & - & 2054 & 2018 & 1.6 \\
\hline \multirow[t]{5}{*}{$\mathrm{CL}$} & \multirow[t]{5}{*}{20 April 2005} & - & 1640 & 1610 & 1663 & 1.4 \\
\hline & & - & 1647 & 1648 & 1632 & -0.9 \\
\hline & & - & 1595 & 1538 & 1571 & -1.5 \\
\hline & & - & 1648 & 1647 & 1663 & 0.9 \\
\hline & & - & 1619 & 1559 & 1610 & -0.6 \\
\hline
\end{tabular}

The second set of field data was obtained from the first large-scale field use of the SSD method at a demonstration of rapid military airfield construction techniques performed in the Northern Territory of Australia. This demonstration took place in 2007 at Bradshaw Field Training Area, approximately $600 \mathrm{~km}$ south of Darwin, Australia (Anderton et al. 2008). The SSD method was the primary tool used to provide quality control for construction of an unsurfaced airfield. It was used to measure dry density in each of four compacted layers.

To compare the effectiveness of the SSD method to conventional field density methods, a nuclear density gauge was used to measure in situ moisture content and dry density alongside the steel-shot tests. Tables 3 and 4 list data from field use of the SSD method in military construction in Australia. Table 3 summarizes the laboratory analyses of the four constructed layers at the site in Australia. The maximum dry densities (MDD) in the table were determined using the modified Proctor method for soil compaction (ASTM 2009b). The optimum moisture content (OMC) that corresponds with the MDD was determined as part of the modified Proctor method. These values represent the maximum density the soil could attain, with the associated water content, under ideal compaction conditions. The specifications for the construction at this site stated that dry density of the completed layers (Table 4) had to be within 98 percent of the values determined in the laboratory (Table 3 ). 


\begin{tabular}{|c|c|c|c|c|c|c|}
\hline Layer & USCS Class & Gravel $^{\mathrm{a}}(\%)$ & Sand $^{\mathrm{b}}(\%)$ & Fines $^{c}(\%)$ & MDD $\left(\mathrm{kg} / \mathrm{m}^{3}\right)$ & OMC (\%) \\
\hline Subbase & SP & 18.4 & 79.2 & 2.4 & 2159 & 6.4 \\
\hline Subgrade & SP-SM & 17.8 & 76.0 & 6.1 & 1945 & 7.3 \\
\hline Coarse base & SP & 37.9 & 59.1 & 3.0 & 2078 & 4.2 \\
\hline Wearing-base & SP & 22.4 & 74.2 & 3.4 & 2074 & 5.3 \\
\hline
\end{tabular}

Note: MDD, maximum dry density for modified Proctor energy level; OMC, optimum moisture content from modified Proctor method; SP, poorly graded sand; SP-SM, poorly graded sand with silt and gravel.

${ }^{\text {a }}$ Soil with a particle diameter greater than $4.75 \mathrm{~mm}$.

${ }^{\mathrm{b}}$ Soil with a particle diameter between 4.7 and $0.075 \mathrm{~mm}$.

${ }^{\mathrm{c}}$ Soil with a particle diameter less than $0.075 \mathrm{~mm}$.

\begin{tabular}{|c|c|c|c|c|c|c|}
\hline Layer & \begin{tabular}{|l} 
No. of \\
Tests
\end{tabular} & \begin{tabular}{|l|} 
Constructed Dry \\
Density - Steel Shot \\
$\left(\mathrm{kg} / \mathrm{m}^{3}\right)$
\end{tabular} & \begin{tabular}{|l|} 
Steel-Shot \\
Standard \\
Deviation \\
\end{tabular} & \begin{tabular}{|l|} 
Constructed Dry \\
Density - Nuclear \\
Density $\left(\mathrm{kg} / \mathrm{m}^{3}\right)$ \\
\end{tabular} & \begin{tabular}{|l|} 
Nuclear Density \\
Standard \\
Deviation \\
\end{tabular} & \begin{tabular}{|l} 
Percent \\
Difference
\end{tabular} \\
\hline Subbase & 3 & 2028 & 69.8 & 1937 & 72.7 & 4.6 \\
\hline Sub grade & 6 & 2042 & 116.9 & 2028 & 24.0 & 0.7 \\
\hline Coarse base & 22 & 2126 & 73.8 & 2126 & 44.0 & 0.0 \\
\hline Wearing-base & 22 & 2111 & 56.2 & 2102 & 35.1 & 0.4 \\
\hline
\end{tabular}

SSD and nuclear density tests were not run at the same 1ocation, but at random points throughout the runway construction. Therefore, the comparison has been made on the average density of all the tests conducted with each device in each material type, not a true side-by-side comparison. Because the runway material had been prepared using an industrial screening machine to remove particles larger than $12.7 \mathrm{~mm}$, this material was treated as homogeneous throughout each layer.

Table 4 presents the averages of the measured dry densities of the four layers of the runway using the SSD method and the nuclear gauge method. Similar to the first set of data from field trials (Table 2), values in Table 4 show that in three of the four materials tested during runway construction, the difference in measured density between the two methods was less than 1 percent. In the fourth material, the difference was approximately 5 percent. The difference was higher than expected, but could be due to several factors, including minor differences in moisture content, larger percentage of gravel in the test area, or operator style.

A third set of field data from military-support operations in southern Iraq was also analyzed. This use was not related to road construction, but instead supported tests of sensor response in Middle Eastern soils. The data were derived from use of the drive-cylinder method to measure soil density in a 2-m deep trench and use of the SSD method in an adjacent trench of the same depth. Soils exposed in the trench walls comprised distinct layers of sand with gravel (SP), silty sand (SM), and gravelly sand (SW). It was anticipated this data may provide a comparison of the SSD and density-drive methods in a coarser grained, gravelly material (SW up to 30 percent gravel). Sampling and testing soils from these trenches is described by Wakeley et al. (2009). However, the gravelly samples were also partially bonded with natural mineral cement that resulted from evaporation in a hot, dry climate. Field observations indicated that the drive cylinder was not 
capable of capturing a representative sample in the gravels, and compromised the intrinsic texture of the soil. The drive-cylinder method yielded density values that were more than 5 percent lower than the density measured using the SSD method for most samples from corresponding soil layers in the two trenches. These low densities are attributed to the adverse influence of gravel, in agreement with the findings of Noorany et al. (2000).

CONCLUSIONS: Applications of the steel-shot density method to desert soils have shown that the test can be performed rapidly with minimal start-up training. The method is repeatable and logistically friendly. It provides a simplified and reliable option for measuring soil density in a range of field conditions and soil types, including compacted clay, silty sands, and gravelly sands. Ease of recovery and reuse of the steel shot is particularly advantageous in expedient construction and military engineering, where time and supplies are limited. The ease of using this method makes training simple, which is advantageous where personnel changes are frequent. The method has the advantages of an easily reusable medium and simple equipment and techniques, relative to other standard methods, and it avoids the logistical difficulties associated with the energy source of a nuclear density gauge. Data from the soils tested, including silty sand, lean clay, and sand, show that this method produces density values within 2 percent of the values derived from traditional methods. More data comparing the SSD method to the sand-cone method and the nuclear device in gravelly soils are needed to confirm the SSD method's accuracy and reliability in this soil type.

ACKNOWLEDGEMENTS: The authors commend the efforts of the field teams who sampled soils and measured soil density and moisture in difficult conditions in Australia and in even more challenging conditions in Iraq. Permission to publish this paper was granted by the Director, Geotechnical and Structures Laboratory, U.S. Army Engineer Research and Development Center.

\section{REFERENCES:}

Abaza, O. A. 2006. Assessment of nuclear density measurements in the quality control of highway construction. Materials Technology Journal 21(4):225-229.

Anderton, G. L., E. S. Berney IV, T. A. Mann, J. K. Newman, E. A. Baylot, D. K. Miller, and Q. Mason. 2008. Joint Rapid Airfield Construction (JRAC) 2007 technology demonstration. ERDC/GSL Technical Report TR-08-17. Vicksburg, MS: U.S. Army Engineer Research and Development Center.

American Society for Testing and Materials (ASTM). 2004. Standard test method for density of soil in place by the drive-cylinder method. ASTM standard D 2937-04. West Conshohocken, PA: American Society for Testing and Materials (ASTM) International.

ASTM. 2006. Standard practice for classification of soils for engineering purposes (Unified Soil Classification System). ASTM standard D 2487-06. West Conshohocken, PA: American Society for Testing and Materials (ASTM) International.

2007. Standard test method for density and unit weight of soil in place by sand-cone method. ASTM standard D 1556-07. West Conshohocken, PA: American Society for Testing and Materials (ASTM) International.

2008a. Standard specification for stainless steel bars and shapes. ASTM standard A 276-08a. West Conshohocken, PA: American Society for Testing and Materials (ASTM) International. 
. 2008b. Standard test methods for density and unit weight of soil and rock in place by the sand replacement method in a test pit. ASTM standard D 4914-08. West Conshohocken, PA: American Society for Testing and Materials (ASTM) International.

2008d. Standard test method for in-place density and water content of soil and soil-aggregate by nuclear methods (shallow depth). ASTM standard D 6938-08a. West Conshohocken, PA: American Society for Testing and Materials (ASTM) International.

.2008e. Standard test method for density and unit weight of soil in place by the rubber balloon method. ASTM standard D 2167-08. West Conshohocken, PA: American Society for Testing and Materials (ASTM) International.

2009a. Standard test methods and definitions for mechanical testing of steel products. ASTM standard A 370-09a. West Conshohocken, PA: American Society for Testing and Materials (ASTM) International.

2009b. Standard test methods for laboratory compaction characteristics of soil using modified effort [56000 $\left.\mathrm{ft}-\mathrm{lb} / \mathrm{ft}^{3}\left(2700 \mathrm{kN} \cdot \mathrm{m} / \mathrm{m}^{3}\right)\right]$. ASTM standard D 1557-09. West Conshohocken, PA: American Society for Testing and Materials (ASTM) International.

McCook, D. K., and D. W. Shanklin. 2000. NRCS experience with field density test methods including the sandcone, nuclear gage, rubber balloon, drive-cylinder, and clod test. In Constructing and controlling compaction of earth fills, ed. D.W. Shanklin, K. R. Rademacher, and J. R. Talbot. ASTM STP 1384, 72-92. West Conshohocken, PA: American Society for Testing and Materials.

Noorany, I., W. S. Gardner, D. J. Corley, and J. L. Brown. 2000. Variability in field density tests. In Constructing and controlling compaction of earth fills, ed. D. W. Shanklin, K. R. Rademacher, and J. R. Talbot. ASTM STP 1384, 58-71. West Conshohocken: American Society for Testing and Materials.

Wakeley, L. D., J. R. McKenna, J. R. Kelley, T. E. Berry, S. S. Jackson, S. G. Bourne, and E. Villanueva. 2009. Protocol for field sampling of soils to support soil-sensor and IED blast-phenomenology modeling. ERDC Technical Report TR-09-1. Vicksburg, MS: U.S. Army Engineer Research and Development Center.

NOTE: The contents of this technical note are not to be used for advertising, publication, or promotional purposes. Citation of trade names does not constitute an official endorsement or approval of the use of such products. 